Original Research Paper

\title{
A New Hybrid AHP-TOPSIS Method for Ranking Human Capital Indicators by Normalized Decision Matrix
}

\author{
Abdul Kadar Muhammad Masum, A.N.M. Rezaul Karim, \\ Faisal Bin Al Abid, Saiful Islam and Mohammad Anas \\ Department of Computer Science and Engineering, International Islamic University Chittagong, Bangladesh
}

\author{
Article history \\ Received: 09-07-2019 \\ Revised: 14-11-2019 \\ Accepted: 04-12-2019 \\ Corresponding Author: \\ A.N.M. Rezaul Karim \\ Department of Computer \\ Science and Engineering, \\ International Islamic University \\ Chittagong, Bangladesh \\ Email: zakianaser@yahoo.com
}

\begin{abstract}
Human Capital or HC plays a significant role in the field of economic growth. Advancement on human capital and knowledge-based economy are of core importance for developing countries. Active representatives of capital accumulation are the people and utilizing natural resources for contributing to the socio-economic growth of the country. Evaluation of HC helps organizations to concern about their present position taking Human Capital Management into account. The core goal of this work is to measure performance of each organization individually based on criteria and rating the individual depending on the measurements. The technique used in this paper is based on the integration of "AHP" and "TOPSIS" as "AHPTOPSIS" Hybrid method. The Analytic Hierarchy Process determines criteria's weight and significance of the indicators or alternatives. The final ranking of $\mathrm{HC}$ is done by TOPSIS method considering the importance of the indicators. The proposed MCDM approach is effective, compatible and reliable considering the goal of the study.
\end{abstract}

Keywords: AHP-TOPSIS, Human Capital, MCDM, Decision Matrix

\section{Introduction}

The decision matrix comprises rows and columns that make it possible to allow the assessment of options related to different criteria for the decision. In today's era, Human Capital (HC) is one of the most prominent classifications of Intellectual Capital (IC) (Lazim et al., 2013). HC was basically developed in 1960 by economist group collaborating with the University of Chicago at Becker in 1964 (Lazim et al., 2013). In 1998, Huszc defined $\mathrm{HC}$ as to be a function of time, experience, knowledge and potential within an institution. Few experts named Beskese and Kahraman defined $\mathrm{HC}$ to be of utmost important aspect acting as a source of originality and innovation (Lazim et al., 2013). People represents one of the key strategic resource of an organization and with which all other resources either material or nonmaterial resources are connected. Thus, the ultimate success, creativity and efficiency of an organization or institution depend upon the quality of its employees.

Human Capital is one of the greatest determinants of economic growth for a country. A new system named Human Capital Index introduced by World Bank ranks countries depending on the progress of the country in rising human capital which emphasis nation to invest more effectively in building the people. HC is closely connected to economic growth as it expands country's ability to produce more goods and services. It is the same case in the perspective of Bangladesh. Some researchers deeply observed that the formal connections between growth rate and human capital in developing countries like Bangladesh. The study was regarding the relation of Bangladesh economic growth with its human capital. Bangladesh, similar to other developing countries depends mostly upon labor intensive production process. According to the researchers, these results notifies that increase in human capital have a tendency to maintain growth in per capital GDP. Close attention on human resources should be a priority for Bangladesh. Although Bangladesh has achieved lots of progress in the field of economic growth and more attention should be given to the population assets of Bangladesh. So, the country needs to keep track of the growth in human capital to measure the overall progress in the development.

Evaluation and measurement are the essential components for human management growth. Evaluation plays a vital role in Human Capital (Lazim et al., 2013) and it contributes much to Human Capital evaluation by applying some common survey in statistical technique. Later, the statistical method was improved by Vittadini and Lovagtio (Lazim et al., 2013). 
New analysis techniques have been developed with rapid improvement of technology. In this study, we use a model of "Multi Criteria Decision Making (MCDM)" (Gür et al., 2016) for handling a number of dissimilar and inconsistent criteria while selecting among preplanned decision alternatives. Under MCDM approach there are two methods called AHP and TOPSIS are used. We used "Analytic Hierarchy Process" (AHP) (Görener, 2012) to find out the relative importance of alternatives by using pair-wise comparison of alternatives based on some pre-defined criteria. Also, when weight of the criteria has been adjusted, AHP can split-up decision problem. "Technique for Order Preference by Similarity to Ideal Solution (TOPSIS)" is used for discovering the best and worst alternative ideals.

Our proposed approach provides strong outcome when the sensitivity is carried on the criteria's weight. In the last step, various distance functions are examined and the effects of the results are noticed. A comparison between proposed approach and the existing studies concludes that the proposed approach contains variability in a real way and more precise outputs.

\section{Literature Review}

The process of selection of organizations through technological advancement has been the main concentration in different academic analysis. Majority of the methods in the literature belong to the MCDM approach. The selection process is usually depicted as a MCDM technique because different aspects can be used to assess the alternatives of IS.

Recent IT selection processes are as follows: Analytic Network Process (ANP) (Kadoić et al., 2017) united with Base overhead cost recovery (BOCR) method are used by Liang and Li (2008; Oztaysi, 2014) which assess the alternatives from different perspectives. This methodology is applied to 4 Enterprise Information System alternatives. According to (Yazgan et al., 2009) Artificial Neural Networks (ANN) and ANP can be both utilized for selection of ERP software. Multiple risk situations can be dealt by using practical choices for project evaluation according to (Chen et al., 2009).

Zavadskas et al. (2010) proposed a technique by the application of SAW-G and TOPSIS Grey techniques. Jaskowski et al. (2010) created weights utilizing fuzzy AHP method. Mahmoodzadeh et al. (2007) utilized both AHP and TOPSIS to accurately rank various projects based on some selected criteria.

An organization needs to take lots of decisions on a daily basis. Often the decision makers find difficulty in selecting the optimal alternative in presence of certain limitation. MCDM is a relative technique for making decision. The MCDM method is a dynamically developing approach in the field of decision making research. Various approaches are used by different authors for evaluating the human Capital (HC) of different organizations. Some works regarding $\mathrm{HC}$ are listed as follows (Karabašević et al., 2018). The purpose of the study was to solve the problem of personnel selection in the human resource management by applying Stepwise Weight Assessment Ratio Analysis (SWARA) method and Weighted Sum Preferred Levels of Performance (WSP LP) method. The SWARA method ordains the criteria weight and for each alternative WSPLP method decides upon the total performance rating (Gholipour and Ebrahimi, 2018). The established model in this paper evaluates the Human Capital (HC) of various municipal districts. The model works in three step. Firstly, the related $\mathrm{HC}$ criterions are selected, then the weight of the criterions are calculated based on comparative importance. Finally, the municipal districts are ranked according to the weight of the criterion for which a Fuzzy Multiple Criteria Decision Making technique such as Fuzzy TOPSIS was applied (Bozbura and Beskese, 2007). The author suggested a "Fuzzy Analytic Hierarchy Process (AHP)" for uplifting institutional capital measurement indicators under particular conditions (Görener, 2012). In addition to these, experts also applied Fuzzy MCDM approaches like VIKOR technique for the solution of the employee training selection issue, the Fuzzy "DEMATEL-ANP" MCDM methodology for employee selection, the implementation of the combined "MCDM" approach to selection of Personnel, selection of applicants in the industrial mining.

In this research paper, the criteria are decided and pairwise comparison matrix was used to find out criteria's weight. Pairwise comparison matrix was constructed with respect to each criterion of alternatives. After calculating the values of all the alternatives, multiplication of each alternative was accomplished by corresponding criterion weight and all the values of a single alternative are summed up. The final result gives the total value that indicates the importance of each alternative. This AHP method is employed to find the criteria weights. The ranking of the alternatives are done according to their importance using TOPSIS method.

\section{Methodology}

The AHP is basically a theory of quantification. In multilevel hierarchy structure AHP is used to acquire comparative priorities from definite and continual paired analogy on absolute scale. The relative range of choice is the scale of measurement in this research. AHP measures the link between the groups of components within its structure. AHP is one of the renowned and popular ways of using MCDM methods and is a nonlinear framework which does not prefer any guesses regarding deduction and induction. Prof. Thomas L. Saaty's developed AHP which is known to be a reliable method for finding out 
the alternatives based on their significance considering the criteria. Resolution of Complex decisions is accomplished by arranging the alternatives in a hierarchical structure. Through pairwise comparison of the alternatives, the hierarchical framework is developed. The AHP process works as follows:

- $\quad$ Find out the unordered problem

- $\quad$ Find the criteria and alternative

- Selection of decision elements through pairwise comparison

- The relative weights of the decision components are predicted using eigenvalue method

- The consistent characteristic of matrix is checked

- All the weight of the decision elements is collected

The fundamental scale of comparison has been given as the scale from 1 to 9 where 1 indicates same importance, 2,4,6,8 indicates medium importance, 5 reveals strong importance, 7 indicates highest importance. Last but not the least, 9 reveals the extreme importance (Rouyendegh et al., 2014).

The ranking of the alternatives is accomplished by TOPSIS method. For analyzing the contents of a "decision matrix", "AHP-TOPSIS" Hybrid method was used. We considered $\mathrm{p}$ alternatives and $\mathrm{q}$ to be the number of decision criteria. Each alternative is assessed taking $\mathrm{q}$ decision criteria into consideration. A decision matrix is formed by giving input to the alternatives. The steps of AHP-TOPSIS Hybrid methodology is given below.

AHP-TOPSIS hybrid method given as follows:

Step 1: First of all, the alternatives were determined. Following list of alternatives were selected using $A=\left\{A_{1}, A_{2} \ldots A_{p}\right\}$

Step 2: Criteria were selected as $C=\left\{C_{1}, C_{2} \ldots C_{q}\right\}$

Step 3: Criteria's weight was identified by using AHP and taking opinion of the experts $\left(W_{i}\right)$ into account. The decision makers were assigned the task of creating separate pairwise comparisons by using standard scale of nine levels described above.

Step 4: Decision matrix was identified using:

$\mathrm{D}=\left[\begin{array}{lllllll}\mathrm{c}_{11} & \mathrm{c}_{12} & \mathrm{c}_{13} & . & . & . & \mathrm{c}_{1 q} \\ \mathrm{c}_{21} & \mathrm{c}_{22} & \mathrm{c}_{23} & . & . & . & c_{2 q} \\ c_{31} & c_{32} & c_{33} & . & . & . & c_{3 q}\end{array}\right]$

$A_{k}$ indicates the alternative in $k^{\text {th }}$ criterion, relating $K t h$ alternative; $C i j$ indicates the alternatives performance rating.

Step 5: The normalized decision matrix was found out using the following formula:

$$
r_{p q}=\frac{c_{p q}}{\sqrt{\sum_{q=1}^{p} c_{p q}^{2}}}
$$

Step 6: Weighted normalized decision matrix was discovered. Wireveals the weight of the $1^{\text {th }}$ criterion:

$$
V_{p q}=W_{p} X f_{p q}, p=1,2,3 \ldots \ldots, P ; q=1,2,3 \ldots \ldots, Q
$$

Step 7: The definition of positive (PIS) and negative ideal solution (NIS) was given as follows:

PIS and NIS have to be determined using $A^{*}$ and Aas follows:

$$
\begin{aligned}
& A^{*}=\left\{v_{1}^{*}, v_{2}^{*}, v_{3}^{*} \ldots v_{q}^{*}\right\}= \\
& \left\{\left(\max _{p q} \mid p \in P^{\prime}\right),\left(\max _{p q} \mid p \in P^{q}\right)\right\} \\
& A^{-}=\left\{v_{1}^{-}, v_{2}^{-}, v_{3}^{-} \ldots v_{q}^{-}\right\}= \\
& \left\{\left(\max _{p q} \mid p \in P^{\prime}\right),\left(\max _{p q} \mid p \in P^{q}\right)\right\}
\end{aligned}
$$

Step 8: Closeness or the measurement of separation was calculated among the alternatives

$S i^{*}$ and $\mathrm{Si}$ - for each alternative was calculated from positive as well as negative ideal solution:

$$
\begin{aligned}
& \mathrm{D}_{\mathrm{q}}^{*}=\sqrt{\sum_{p=1}^{k}\left(v_{p q}-v_{p}^{*}\right)^{2}}, q=1 \text { to } Q \\
& \mathrm{D}_{\overline{\mathrm{n}}}=\sqrt{\sum_{p=1}^{k}\left(v_{p q}-v_{\bar{p}}\right)^{2}}, q=1 \text { to } Q
\end{aligned}
$$

Step 9: Best alternatives were found out using the following formula:

$$
C C_{q}^{*}=\frac{D_{q}^{-}}{D_{q}^{*}+D_{q}^{-}}, q=1,2,3 \ldots Q
$$

We have implemented the above method by using $\mathrm{C}++$ programming language. AHP (https://github.com/raihan02/My_Profile-

/blob/master/AHP_FINAL.cpp) and TOPSIS (https://github.com/raihan02/My_Profile-

/blob/master/TOPSIS.cpp) are implemented separately according to the above methodology.

\section{Case Study}

The application of Hybrid AHP-TOPSIS method can be understood from the following example. The 
measurement of the performance has been done according to the criteria listed as follows:

C1: Strategy Integration (SI), C2: Cultural Relevance (CR), C3: Knowledge Management (KM), C4: Talent (T), C5: Leadership (L).

To evaluate the performance of the individual in Human Capital, the above criteria have been used. The rating of four personnel alternatives $(\mathrm{H} 1, \mathrm{H} 2, \mathrm{H} 3, \mathrm{H} 4)$ have been accomplished in this section.

\section{Ranking of Individual using AHP-TOPSIS}

The response of the questionnaire and discussion with the decision makers was used to create a matrix.

Table 1 shows the criteria matrix.

After obtaining the above matrix, the weight of each criterion is found by using AHP technique and the weights are represented in the Table 2.

Table 2 clearly indicates that the Strategy Integration shows the maximum weight among all other criteria considered for estimation. So Strategy Integration is the most important factor for ranking performance. The consistency ratio can be calculated using:

$$
\mathrm{CR}=0.07 / 1.12=0.0625
$$

Now if the consistency ratio CR is less than $10 \%$, it is considered to be a consistent judgment. Hence there is no contradiction in the judgment. After the completion of AHP technique, the method of TOPSIS is introduced which assess the alternatives based on recommended criteria's as given in Table 3.

During evaluating through TOPSIS technique, in the first step $_{p q}$ was calculated using Equation (2). In the next step, $v_{p q}$ is calculated by multiplying each column by $w_{p}$. Afterwards, ideal and negative ideal solution $\mathrm{A}^{*}$ and $\mathrm{A}^{-}$are calculated respectively. Finally, calculated Equation (7) was used to find out the relative closeness of ideal solutions and was presented as the following in Table 4.

Figure 1 show the ranking of the alternative where performance of $\mathrm{H} 2$ is the best among all other alternatives.

Table 1: The criteria matrix

\begin{tabular}{llllll}
\hline & $\begin{array}{l}\text { Strategy } \\
\text { Integration (SI) }\end{array}$ & $\begin{array}{l}\text { Cultural } \\
\text { Relevance (CR) }\end{array}$ & $\begin{array}{l}\text { Knowledge } \\
\text { Management (KM) }\end{array}$ & Talent (T) & Leadership (L) \\
\hline $\begin{array}{l}\text { Strategy Integration (SI) } \\
\begin{array}{l}\text { Cultural } \\
\text { Relevance (CR) }\end{array}\end{array}$ & 1 & 5 & 3 & 2 & 4 \\
$\begin{array}{l}\text { Knowledge } \\
\text { Management (KM) }\end{array}$ & $1 / 5$ & 1 & $1 / 3$ & $1 / 3$ & $1 / 5$ \\
$\begin{array}{l}\text { Talent (T) } \\
\text { Leadership (L) }\end{array}$ & $1 / 3$ & 3 & 1 & $1 / 4$ & 5 \\
& $1 / 2$ & 3 & 4 & 1 & 2 \\
\end{tabular}

Table 2: Weights of the criteria

\begin{tabular}{lc}
\hline Criteria & Weight \\
\hline Strategy Integration & 0.380 \\
Cultural Relevance (CR) & 0.056 \\
Knowledge Management (KM) & 0.182 \\
Talent (T) & 0.254 \\
Leadership (L) & 0.126 \\
\hline
\end{tabular}

Table 3: The decision matrix

\begin{tabular}{llllll}
\hline Human capital & Integration of strategy & Relevance to culture & Knowledge management & Talent (T) & Leadership (L) \\
\hline H1 & 6 & 4 & 5 & 8 & 3 \\
H2 & 8 & 6 & 6 & 9 & 5 \\
H3 & 8 & 5 & 5 & 8 & 4 \\
H4 & 4 & 6 & 4 & 7 & 3 \\
\hline
\end{tabular}

Table 4: Ranking result of alternative

\begin{tabular}{lll}
\hline Alternative & Importance & Rank \\
\hline H1 & 0.4659 & 3 \\
H2 & 1.0000 & 1 \\
H3 & 0.7999 & 2 \\
H4 & 0.0769 & 4 \\
\hline
\end{tabular}




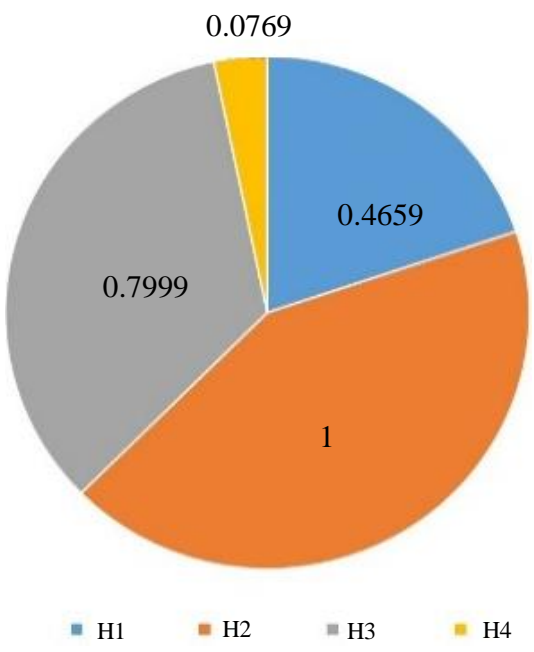

Fig. 1: Ranking shown in pie chart

\section{Conclusion}

Human Capital is an asset consisting of the knowledge and skills that an individual holds and is utilized by an organization to enhance its objective. For ensuring improvement in Human Capital Management, $\mathrm{HC}$ evaluation must be defined with the significance of its indicators or alternatives. This study uses five criteria based on which four alternatives are evaluated. The most important criteria were determined using AHP. As the criteria matrix indicates, the Strategy Integration represents the maximum weight of 0.38 and so is the most important factor for ranking performance. The Talent and Knowledge Management criteria occupy the position of second and third important criteria. The Cultural Relevance having weight of 0.56 is considered to be the least important criteria. Finally, the "TOPSIS" approach is applied to determine each alternative's performance rating as a whole. The result of the TOPSIS shows that the $\mathrm{H} 2$ alternative obtains higher importance and rank than the other three alternatives.

Our proposed method takes a smaller number of inputs than the existing Fuzzy AHP and AHP methods. We take the input only for the pairwise comparison matrix of the criteria, but the existing methods take the input for both criteria and alternatives. So, the number of pairwise comparison matrix for the existing methods is huge. The weights of the criteria are inaccurate in existing Fuzzy AHP-TOPSIS (Rituraj and Shivam, 2018) method because it takes the linguistic variables of the criteria. But we take the exact numeric value for each criterion and then calculate the accurate weights of the criteria. TOPSIS or FUZZY TOPSIS method calculate the average weight of the criteria that's why the final ranking of the alternatives is not accurate. To get the accurate final ranking of the alternatives we take weight of the criteria from the output of the AHP method.
The proposed approach of AHP-TOPSIS gives more accurate result in such case and is more real.

\section{Acknowledgement}

We thank Almighty Allah for His protection throughout the time of this research work and those who contributed to make this work a success.

\section{Authors Contributions}

The contributions made by each author in the preparation, development and publication of this manuscript.

\section{Ethics}

This article contains original and unpublished content. The corresponding authors point out that the manuscript has been read and approved by all other authors and does not involve any ethical issues.

\section{References}

Bozbura, F.T. and A. Beskese, 2007. Prioritization of organizational capital measurement indicators using fuzzy AHP. Int. J. Approximate Reason., 44: 124-147. DOI: 10.1016/j.ijar.2006.07.005

Chen, T., J. Zhang and K.K. Lai, 2009. An integrated real options evaluating model for information technology projects under multiple risks. Int. J. Project Manage., 27: 776-786.

DOI: 10.1016/j.ijproman.2009.01.001

Gholipour, A. and E. Ebrahimi, 2018. Fuzzy multicriteria decision making approach for human capital evaluation of municipal districts. Int. J. Human Capital Urban Manage., 3: 1-8. 
Gür, Ş., M. Hamurcu and T. Eren, 2016. Selection of academic conferences based on analytical network processes. Multiple Criteria Dec. Mak., 11: 51-62. DOI: $10.22367 / \mathrm{mcdm} .2016 .11 .04$

Görener, A., 2012. Comparing AHP and ANP: An application of strategic decisions making in a manufacturing company. Int. J. Bus. Soc. Sci.

Jaskowski, P., S. Biruk and R. Bucon, 2010. Assessing contractor selection criteria weights with fuzzy AHP method application in group decision environment. Automat. Constr., 19: 120-126. DOI: 10.1016/j.autcon.2009.12.014

Kadoić, N., N.B. Ređep and B. Divjak, 2017. Decision making with the analytic Network process. Proceedings of the 14th International Symposium Operational Research, Sept. 27-29, Bled, Slovenia, pp: 180-187.

Karabašević, D., D. Stanujkić, B. Đorđević and A. Stanujkić, 2018. The weighted sum preferred levels of performances approach to solving problems in human resources management. Serbian J. Manage., 13: 145-156. DOI: $10.5937 / \operatorname{sjm} 13-12589$

Lazim, A., J. Sunadia and T. Imran, 2013. Ranking of human capital indicators using analytic hierarchy process. Soc. Behav. Sci., 107: 22-28. DOI: 10.1016/j.sbspro.2013.12.394

Liang, C. and Q. Li, 2008. Enterprise information system project selection with regard to BOCR. Int. J. Project Manage., 26: 810-820.

DOI: 10.1016/j.ijproman.2007.11.001
Mahmoodzadeh, S., J. Shahrabi, M. Pariazar and M.S. Zaeri, 2007. Project selection by using fuzzy AHP and TOPSIS technique. Int. J. Soc. Manage. Econom. Bus. Eng., 1: 324-329.

Oztaysi, B., 2014. A decision model for information technology selection using AHP integrated TOPSISGrey: The case of content management systems. Knowledge-Based Syst., 70: 44-54. DOI: $10.1016 /$ j.knosys.2014.02.010

Rituraj, C. and L. Shivam, 2018. A hybrid of QFD and AHP-TOPSIS for drug dumping waste projects. J. Project Manage., 3: 143-150. DOI: $10.5267 / \mathrm{j} . j p m .2018 .2 .003$

Rouyendegh, B.D., U. Baç and T.E. Erkan, 2014. Sector selection for ERP implementation to achieve most impact on supply chain performance by using AHPTOPSIS hybrid method. Tehnicki Vjesnik-Technical Gazette, 21: 933-937.

Yazgan, H.R, S. Boran and K. Goztepe, 2009. An ERP software selection process with using artificial neural network based on analytic network process approach. ExpertSyst. Applic., 36: 9214-9222. DOI: 10.1016/j.eswa.2008.12.022

Zavadskas, E.K., T. Vilutiene, Z. Turskis and J. Tamosaitiene, 2010. Contractor selection for construction works by applying SAW-G and TOPSIS grey techniques. J. Bus. Econom. Manage., 11: 34-55. DOI: $10.3846 /$ jbem. 2010.03 